and stupid, as well as the kind and sensible, ways in which we manage our patients. Since it is written by sociologists, much of it is written in their jargon which is often irritating and occasionally almost unintelligible, but its great merit is the challenge it presents to the almost unconscious mantle of superiority that many, if not most, doctors assume in their relation to their patients. The mere fact that we use the word 'patient' rather than 'client', which is more appropriate in today's medicine, makes this point. We often refer to 'difficult patients' - who want to know too much; but seldom of 'difficult doctors' who will not listen or tell enough. Many of the stories in the book recount the discrepancy between patients' desire and ability to control medical encounters that accounts for the feelings of frustration and helplessness that are reported in consumer (patient) satisfaction studies. In other stories we read of doctors' resentment, instead of grateful acceptance, of patients who really do know more about their condition than the doctor (examples are given of recurrent pneumothorax dangerously ignored and psoriasis and migraine being disdainfully handled). Nor is it only doctors who assume and enjoy the sense of power over patients that they feel. Nurses are just as bad. In one ante-natal clinic, with the patient naked and prone, the midwife 'left the room temporarily and I picked up a book I had brought along. She returned and whipped the volume away, instructed me to "lie ready for the doctor" '. Where else in human society would one adult (a nurse) say to another (a sociologist) who on a hot day, was going to the balcony for a breath of air: "You mustn't do that, you might catch cold ?"

After all the stories have been told, the editors summarise the difficulties that people meet in their professional encounters with doctors and their colleagues. They recount the various roles patients have to play, and the written but unexplained rules that they have to follow if they are not to get into trouble: 'You should have insight into your own condition, but you are not entitled to all the information; you are expected to be a competent patient, but in all matters medical you are assumed to be incompetent'. The stark absurdity of this professional attitude in relation to modern chronic diseases, where the patient very often understands much more about practical management than the doctor who has never had the disease can ever possibly learn, is humbling.

The ethical component in all this may not at first be obvious. But many of the problems of patients are due to insensitivity and lack of caring by medical professionals. Insofar as insensitivity and lack of care lead to bad medicine, these are professional faults; but they are also ethical failures. That there is an evil component in our professions' actions and inactions described in this book is shown by a brief, scathing review of it in one of the free medical newspapers that GPs receive. This ended: "I had to read this book: you don't". If only the obscure sociological jargon were to be re-written in simple English I would regard this book as necessary reading for all doctors and nurses before qualification.

\section{M FLETCHER}

\section{The Role of Medicine: Dream, Mirage or Nemesis?}

Thomas McKeown

Nuffield Provincial Hospitals Trust, London, 1976

Has medicine contributed to an improvement in health ? To most of us the answer seems surely to be yes. Yet, here, in a slim volume which pulls together and reviews an extensive programme of work on changes in mortality over time, Thomas McKeown, Professor of Social Medicine at Birmingham, calls this into question. To take McKeown seriously is without doubt to confront some of the basic assumptions of clinical medicine.

Part One deals with factors contributing to improved mortality rates over the last two centuries or so. In essence, McKeown claims that three broad factors have been at work, environmental, behavioural and therapeutic. Environmental changes include principally improvements in nutrition, but also hygienic measures, i.e. improvements in water supply, better food preparation and better personal habits of cleanliness. Behavioural changes concern mainly the voluntary limitation of family size. Therapeutic measures cover immunisation and treatment, these last being the active measures which arise from developments in medical science. These three factors became effective respectively from the I8th century, I9th century andes? 20th century. Furthermore, the order of the intervention in times? was also the order of their effective $=0$ ness. Older readers will know thato this interpretation is supported by a closely and carefully argued con- sideration of material on mortality in England and Wales. It is ac-w companied here by two additionatapproaches. First, attention is paid to specific medical advances an $\omega_{\omega}$ to the small contribution they cand be said to have made to the total decline in mortality. This is discussed mainly in Part Two in a Chapter on medical research:Secondly, there is what McKeown? calls a conceptual approach. Readers will begin to appreciate that it is the general theory of populations within which McKeown is operating which marks him off so distinctly from the clinician. It enables him both to clarify and attack the mechanistic model of the latter, focused as it is on processes internal to the in dividual and ignoring as it does wider issues of aetiology. Textbooks $\frac{\partial}{\bar{D}}$ McKeown points out, rarely include్ a full discussion of the origins and nature of the disease process. The demographic transition (from higlo mortality and high fertility to low mortality and low fertility) alters ou? resistance to disease, and produce a new kind of adaptation to the environment.

In Part Two, the arguments ar of a different order. The evidence is more sparse and the points are more polemical. A chapter on health services, being quite consistent witl the evaluation of relative contri butions to health starts with nue trition and the importance of foof subsidies, moves to changes if personal behaviour, namely smoking habits and sedentary living, an attacks with vigour the fragmentary nature of the medical input t $\bar{Q}$ environmental measures. Only the is the question of personal healt services addressed, and the focus of acute cases to the neglect of mentat illness and chronic care, which manळ criticise on simple humanitaria. terms, is here subject to question of what amounts to cost-benefit terms

Five major changes to the cur riculum are next set out crisply in 8 chapter which considers a new and more appropriate medical education \title{
.
}


Attention turns to medical research. Just what has been the contribution of medical science and within this, of personal measures and nonpersonal measures such as hygiene and better food? McKeown challenges those who would see biomedical research as the major contributor to solving current health problems. Finally, he faces certain arguments already advanced on the promise and limits of mudern medicine. McKeown's perspective gives rise to as many important challenges of critics such as Illich, and Dubos as it does to those who see a shining future for medicine in its current form.

There is no serious contesting in my view of the painstaking way in which the empirical material on mortality is marshalled. McKeown's work is a model of its kind. But there are issues of interpretation, as one example will show. The DHSS document Prevention and Health leans heavily on the Mckeown argument, drawing the same graphs to illustrate how the decline in mortality began. But the graphs are on a logarithmic scale. Improvement of health is thus duly shown in the case of the major infectious diseases to date from way back before medical advance but the rate of improvement is shown to have increased dramatically once innovations occurred. The McKeown representation makes a different point, namely that medicine mopped up little of the total improvement viewed over a longer span. There simply wasn't that much left to improve! The DHSS presentation is more favourable to medicine; radical statisticians, however, have leapt to a defence of the McKeown presentation, using it as a plank to advocate a more limited role for medicine than McKeown favours!
Actually, of course, both rates and totals are part of the complex picture of achievement and bear on contemporary strategies for action.

This question of implications for action is an intriguing one which deserves fuller consideration. What makes it particularly complex is that we are dealing today, as McKeown so clearly shows, with a different population in a different environment. In such changed conditions I, for one, would welcome more discussion of now past evidence is relevant and what the ground rules for extrapolating from the past are. Accepting that in the 19th Century environmental changes reduced mortality in ways not then well understood, it does not follow that in modern conditions we should necessarily call for more of the same. And the further McKeown delves into specific measures the more blurred, for me, become the distinctions between environmental sciences, medical sciences and therapeutics. Is McKeown not using medical science in his classification of diseases as air-borne, water-borne and so on and in his advocacy of a major distinction between diseases present at fertilisation and those not?

McKeown's clarion call for change will provoke varied reactions depending on where one stands in the spectrum of service providers, researchers and educationalists. As a medical sociologist, I am intrigued by the limits of his plea for a broadened aetiology. Take for example, his recommendations for changes in individual behaviour smoking, diet, exercise and so on. These, to me, are not individual behaviours to be changed at an individual level. They are determined by the social and economic circumstances in which we live particularly the latter, in the sense of our economic and physical $\stackrel{\otimes}{\stackrel{D}{2}}$ situation as producers and ourm manipulation as consumers in $a \stackrel{\bar{\lambda}}{\text {. }}$ profit market industrialised society. His determinants of health are $\Rightarrow$ themselves determined in ways we need to consider if we are to reduceo mortality. Take, again, the recommendation on environmental health $\frac{\overline{\bar{s}}}{\mathrm{~s}}$ and remarks on allied health care $\vec{\Phi}$ workers. In both cases McKeown is for expansion of the doctor's role कs rather than fundamental recon- $\overrightarrow{0}$ sideration of the boundaries of medical responsibility and the di- $\vec{\omega}$ vision of labour between workers of $\Phi$ different kinds. The argument on allied health care workers is a $\odot$ somewhat disingenous one, however. if

This makes McKeown out in some sense to be a conservative critic. 오 Given the reception of his work 0 among doctors this might seem surprising. But he is not to be $\vec{c}$ counted among the doctor-bashers, those who would see medicine $\overparen{\Phi}$ as all-to-powerful, as extending $\vec{\varphi}$ beyond its legitimate area of expertise, Nor is he in the camp of those who regard doctors as victims, caught up in the administrative apparatus of an injust or unequal $\frac{}{0}$ society. All the same, he does challenge the status quo, and does so $\Phi$ in a more basic way than, say Cochrane. Readers of this journal $\overrightarrow{0}$ will want to familiarise themselves 3 with all the critics of medicine. But among these, McKeown's con-? tribution, stemming as it does from

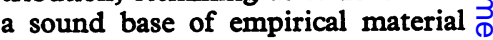
and a different theoretical model, is $\frac{0}{0}$ one we cannot afford to ignore.

\section{Reference}

${ }^{1}$ Radical Statistics Health Group (1976). Whose Priorities ? Radical Statistics: Health Group pamphlet No. $r$.

CELIA DAVIES N 